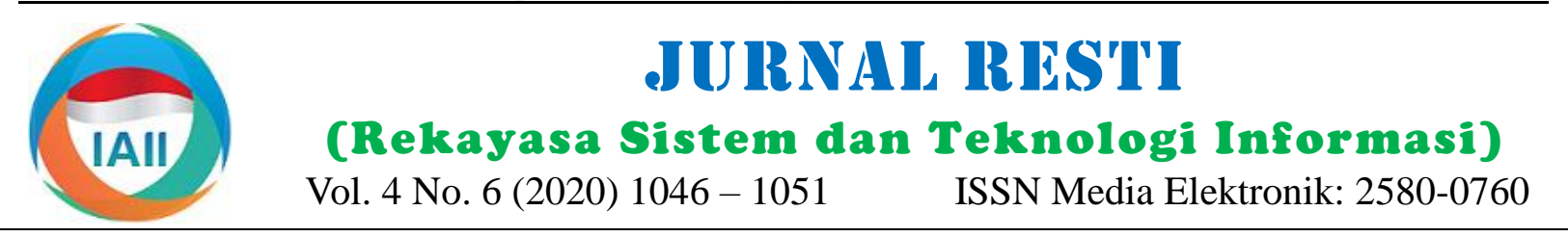

\title{
Implementasi Metode Jaccard pada Analisis Investigasi Cyberbullying WhatsApp Messenger Menggunakan Kerangka Kerja National Institute of Standards and Technology
}

\author{
Panggah Widiandana ${ }^{1}$, Imam Riadi ${ }^{2}$, Sunardi $^{3}$ \\ ${ }^{1}$ Program Studi Teknik Informatika, Universitas Ahmad Dahlan \\ ${ }^{2}$ Program Studi Sistem Informasi, Universitas Ahmad Dahlan \\ ${ }^{3}$ Program Studi Teknik Elektro, Universitas Ahmad Dahlan \\ 11panggah1808048029@webmail.uad.ac.id, ${ }^{2}$ imam.riadi@is.uad.ac.id, ${ }^{3}$ sunardi@mti.uad.ac.id
}

\begin{abstract}
The development of information technology is increasingly showing a great influence on human life. Based on the survey, it was stated that every year the users of the WhatsApp application grew very rapidly, in 2015 that was 900 million users, and in 2020 it increased to 2000 million users. This data is following the increasing number of criminal cases, one of which is cyberbullying. The purpose of the research that has been carried out is for an alternative to investigators in investigating digital evidence in cyberbullying cases. The National Institute of Standards and Technology (NIST) method is used to make it easier for researchers to conduct digital forensics on digital evidence with the collection, examination, analysis, and reporting stages. The Jaccard method is used to identify digital evidence with preprocessing stages, weighting words, and using formulas on the words that have been obtained to identify bullying. The results of the research that have been carried out prove that the NIST method can facilitate the investigation process in lifting evidence to the reporting stage of evidence. The Jaccard method can identify bullying at different levels, the highest percentage value of the perpetrator is obtained, namely, $21 \%$ of words identified, $79 \%$ of other words not identified, and the perpetrator with the lowest score obtained $13 \%$ of words identified, other $87 \%$ of words not identified.
\end{abstract}

Keywords: Jaccard, NIST, Digital Forensics, Cyberbullying.

\begin{abstract}
Abstrak
Perkembangan teknologi informasi semakin menunjukkan pengaruh besar bagi kehidupan manusia. Pengguna aplikasi WhatsApp bertambah sangat pesat, pada tahun 2015 yaitu 900 juta pengguna dan tahun 2020 naik menjadi 2000 juta pengguna. Data tersebut diiringi kasus kriminalitas yang meningkat, salah satunya adalah tindakan cyberbullying. Penelitian ini memberikan alternatif bagi investigator dalam melakukan investigasi barang bukti digital pada kasus cyberbullying. Metode National Institute of Standards and Technology (NIST) digunakan untuk mempermudah forensik digital pada barang bukti digital dengan tahapan collection, examination, analysis, dan reporting. Metode Jaccard digunakan untuk mengidentifikasi barang bukti digital dengan tahapan prepocessing, pembobotan kata, dan identifikasi bullying. Hasil penelitian yang telah dilakukan membuktikan bahwa metode NIST dapat mempermudah proses investigasi dalam pengangkatan barang bukti sampai dengan tahap pelaporan barang bukti. Metode Jaccard mampu mengidentifikasi bullying dengan tingkat yang berbeda, pelaku tertinggi yang didapat yaitu $21 \%$ kata teridentifikasi, sedangkan $79 \%$ kata tidak teridentifikasi. Pelaku dengan nilai terendah didapat $13 \%$ kata teridentifikasi, sedangkan $87 \%$ lainnya tidak teridentifikasi.
\end{abstract}

Kata kunci: Jaccard, NIST, Digital Forensics, Cyberbullying. 


\section{Pendahuluan}

Pada perkembangan revolusi industri 4.0, informasi semakin menunjukkan pengaruh yang besar bagi kehidupan manusia. Kemudahan dalam mengakses informasi sangat penting dengan hadirnya internet sangat membantu baik dari segi pemerintahan, pendidikan, kesehatan maupun pribadi. Internet menyediakan media untuk bersosialisasi, memudahkan urusan pekerjaan, serta menambah market atau pangsa pasar merupakan hal yang saat ini diterapkan [1]. Perkembangan teknologi juga ditandai dengan begitu cepat peningkatan penggunaan smartphone di dunia untuk lebih mempermudah akses informasi dengan cepat, kapan saja dan dimana saja. Menurut survei online yang dilakukan oleh Statista terkait perkembangan pengguna smartphone dapat dilihat pada Gambar 1 [2].

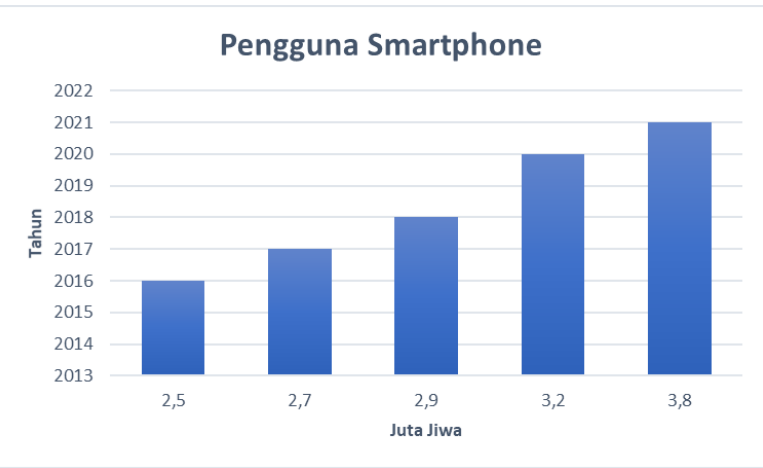

Gambar 1. Penggunan Smartphone di Dunia

Gambar 1 menunjukkan perkembangan pengguna smartphone di dunia. Tahun 2016 pengguna smartphone di dunia mencapai 2,5 Miliar, setiap tahun mengalami peningkatan, hingga menjadi 3,5 Miliar pada tahun 2020. Tahun 2021 kemungkinan pengguna akan bertambah sebesar 0,3 Miliar menjadi 3,8 Miliar. Perkembangan penggunaan smartphone di dunia memacu developer untuk mengembangkan fitur-fitur yang ada didalam media sosial.

Media sosial merupakan salah satu sarana untuk berkomunikasi secara efisien, nyaman, dan populer [3]. Aplikasi media sosial yang paling banyak digunakan adalah WhatsApp. Hal ini dapat dilihat dari 2 juta pengguna, WhatsApp 1,6 juta pengguna, Facebook Messenger 1,4 juta pengguna, WeChat 1,2 juta pengguna, QQ Mobile 800 ribu pengguna, Snapchat 235 ribu pengguna, Viber 230 ribu pengguna, Discord 225 ribu pengguna, dan Telegram 220 ribu pengguna. Data dapat dilihat pada Gambar 2.

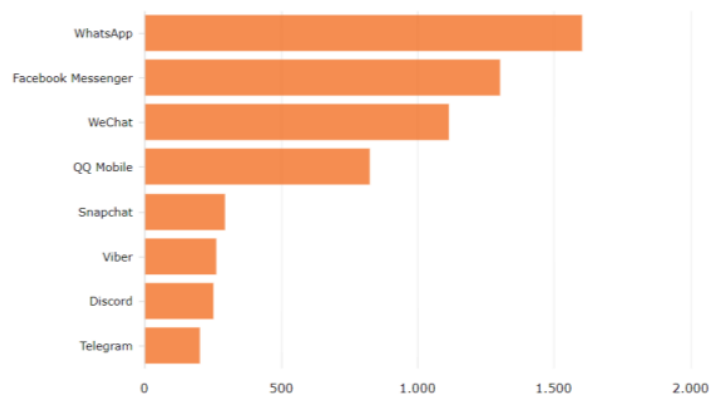

Gambar 2. Jumlah Pengguna Aplikasi Media Sosial

Berdasarkan Gambar 2, pengguna aplikasi WhatsApp bertambah sangat pesat, tahun 2015 terdapat 900 juta pengguna dan pada Maret 2020 naik menjadi 2 Miliar pengguna [4]. Data tersebut membuka peluang bagi tindakan cybercrime dalam aplikasi WhatsApp. Cyberbullying menurut Taskin Tanrikulu (2015) mencakup perilaku teknik relasional berbahaya diarahkan kepada individu, kelompok menggunakan teknologi informasi dan komunikasi [5]. Cyberbullying dapat melalui perantara seperti pesan yang mengandung kata-kata negatif, kata-kata yang dapat mengarah pada tindakan bullying seperti abnormal, pengecut, aneh, banci, bodoh, buruk, gila, jelek, khianat, dan munafik [6]. Dalam melakukan mobile forensics, diperlukan referensi tentang cara menganalisis dan mengidentifikasi cyberbullying di ponsel sehingga lebih mudah untuk menemukan tindakan cyberbullying [7]. Masalah yang sering ditemukan dalam cyberbullying adalah sulit untuk mengidentifikasi korban bahwa pelaku melakukan cyberbullying karena tidak ada bukti kuat untuk membuktikan bahwa kasus cyberbullying telah dilakukan oleh pelaku terhadap korban. Penelitian yang dilakukan tentang Akuisisi Bukti Digital pada Instagram Messenger Berbasis Android Menggunakan Metode National Institute of Justice (NIJ) [8] menghasilkan proses akuisisi barang bukti digital yang berhasil didapatkan di Instagram pada smartphone dalam kondisi root dengan bukti berupa foto dan chatting. Penelitian lain yang serupa adalah Analisis Bukti Digital Facebook Messenger Menggunakan Metode National Institute of Standards and Technology (NIST) [9] menghasilkan teks percakapan, gambar, dan audio pada aplikasi Facebook Messenger. Penelitian yang dilakukan tentang Communication-Efficient Jaccard similarity for High-Performance Distributed Genome Comparisons menghasilkan bahwa algoritma Jaccard dapat terdistribusi untuk menghitung kesamaan dan banyak digunakan dalam analisis data [10]. Penelitian yang sama dengan diatas adalah An efficient recommendation generation using relevant Jaccard similarity yang menghasilkan bahwa metode Jaccard bekerja lebih akurat dan secara efektif menghasilkan rekomendasi yang baik daripada model kesamaan tradisional lainnya [11]. 
Penelitian-penelitian sebelumnya tersebut hanya melakukan akuisisi atau pengangkatan barang bukti. Sedangkan penelitian ini setelah melakukan forensik digital untuk mengangkat barang bukti menggunakan tools forensic yaitu MOBILedit dan selanjutnya dilakukan analisis adanya tindakan cyberbullying. Penelitian dilakukan pada percakapan WhatsAppGroup (WAG) menggunakan kerangka kerja National Institute of Standards and Technology (NIST). Adanya kasus cyberbullying diidentifikasi menggunakan metode Jaccard [12].

\section{Metode Penelitian}

Kerangka kerja forensik yang digunakan dalam penelitian yaitu Metode National Institute of Standards Technology (NIST), text mining untuk membantu mengolah kata agar mempercepat proses identifikasi barang bukti, dan metode Jaccard digunakan untuk proses identifikasi kasus cyberbullying.

\subsection{NIST Method}

Forensik digital diperlukan agar penelitian dapat dilakukan secara terstruktur dan menjadi acuan untuk menyelesaikan masalah [13][14]. Alur NIST dapat dilihat pada Gambar 3 [15].

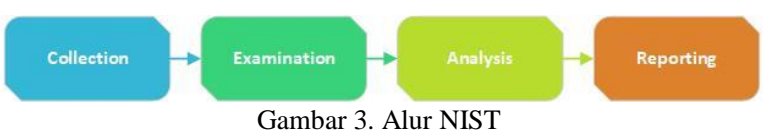

Gambar 3 menjelaskan tentang alur metode NIST yang terdapat empat tahapan [16] [17][18]:

1. Collection merupakan tahapan paling awal, diantaranya melakukan koleksi, dokumentasi, isolasi, dan preservasi barang bukti.

2. Examination melanjutkan tahapan collection diantaranya melakukan backup data dan imaging system yang mendukung format image dan dapat digunakan dengan tool format image.

3. Analysis menggunakan metode yang dibenarkan secara hukum dan tidak merubah teknik untuk mendapatkan informasi yang berguna dan dapat menjawab apa yang dibutuhkan sebagai pendorong untuk melakukan pengumpulan dan pemeriksaan data.

4. Reporting merupakan proses pelaporan yang meliputi penjelasan mengenai alat, dan prosedur yang dipilih, penggambaran tindakan yang dilakukan, memberikan rekomendasi untuk perbaikan kebijakan, prosedur, alat dan aspek lain dalam forensik.

\subsection{Simulasi kasus}

Simulasi digunakan untuk mendapatkan data yang dibutuhkan untuk sampel pada penelitian. Simulasi dilakukan dengan melakukan percakapan dalam sebuah group instant messenger. Salah satu orang didalam group tersebut akan menjadi korban bullying. Simulasi cyberbullying dapat dilihat pada Gambar 4.

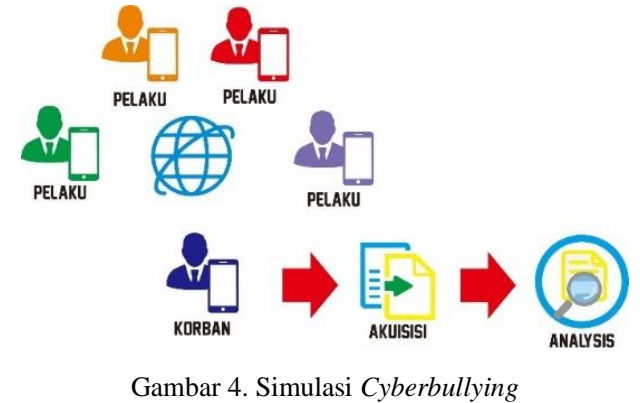

Gambar 4 menjelaskan bahwa ada 5 orang dalam group instant messenger dan salah satunya menjadi korban bullying dalam group tersebut. Korban melakukan pelaporan dan dilakukan akuisisi barang bukti untuk kemudian dilakukan analysis untuk mengidentifikasi kasus cyberbullying.

\subsection{Text Mining}

Text mining atau data mining merupakan metode untuk mengelola data menjadi informasi. Text mining mengolah data teks, sedangkan data mining mengolah data berupa angka atau yang lainnya dari berbagai sumber [19]. Alur text mining dapat dilihat pada Gambar 5 .

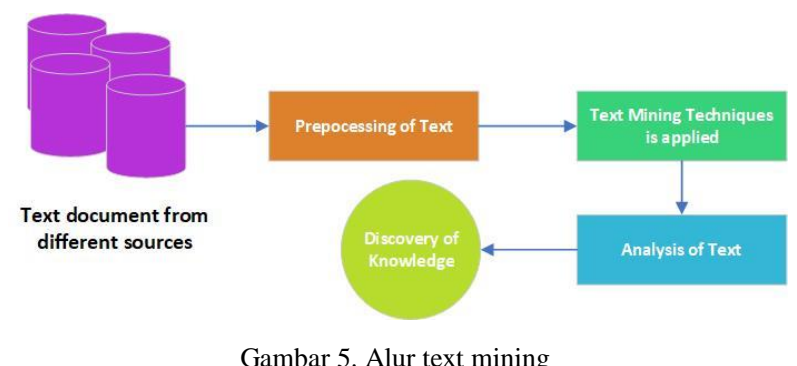

Text mining dimulai dari dokumen mentah melalui prepocessing, penerapan teknik mining dan analysis sehingga mendapatkan pengetahuan. Peran penting diantaranya adalah tahap prepocessing [20] yang terdiri dari case folding, tokenizing, stopword, dan stemming. Case folding adalah merubah huruf besar menjadi huruf kecil. Tokenizing adalah tahap untuk membagi kalimat menjadi kata dan penghilangan delimiter. Stopword adalah menghilangkan kata yang tidak penting dari suatu dokumen dan termasuk penentu, konjungsi, preposisi dan sejenisnya. Stemming adalah pengubahan kata berimbuhan menjadi kata dasar.

\subsection{Jaccard Method}

Jaccard Coeficient adalah salah satu metode yang dipakai untuk menghitung similarity antara dua objects (items) [21]. Jaccard melakukan klasterisasi dokumen dan memiliki fungsi yang baik. Jaccard biasanya digunakan untuk membandingkan dokumen dan menghitung nilai kemiripan (similarity) dari dua objek 
atau dokumen [22][23][24]. Persamaan Jaccard dapat dilihat pada Persamaan 1 [25].

$\operatorname{Jaccard}(X, Y)=\frac{|X \cap Y|}{|X \cup Y|}$

Dengan $X$ adalah Dokumen Query, dan $Y$ adalah dokumen pada percakapan. Contoh perhitungan Jaccard dalam percakapan X "Kenapa kamu bodoh sekali”, query kata negatif adalah Y "bodoh", dengan menggunakan Persamaan (1) maka didapatkan:

$\operatorname{Jaccard}(X, Y)=\frac{\mid \text { bodoh } \mid}{\mid \text { Kenapa kamu bodoh sekali } \mid}$

$\operatorname{Jaccard}(X, Y)=\frac{|1|}{|4|}=0,25 \times 100 \%=25 \%$

\section{Hasil dan Pembahasan}

\subsection{Collection}

Proses investigasi alat dan bahan yang digunakan dalam analisis forensik dapat dilihat pada Tabel 1.

Tabel 1. Alat dan bahan

\begin{tabular}{lll}
\hline No & Nama Alat & Keterangan \\
\hline 1 & Laptop & Proses Akuisisi \\
2. & MOBILEdit Forensics & Software untuk proses akuisisi \\
& Express & \\
3. & Smartphone & Barang bukti korban \\
4. & Kabel USB & Konektor smartphone ke \\
& & Laptop \\
\hline
\end{tabular}

\subsection{Examination}

Tahap examination digunakan untuk melakukan cloning terhadap barang bukti agar tidak terjadi modifikasi atau perubahan sehingga barang bukti tetap dapat dikatakan valid dalam persidangan. Proses akuisisi dilakukan menggunakan aplikasi MOBILEdit Forensics Express.

\subsection{Analysis}

Tahap analysis digunakan untuk mendeteksi barang bukti hasil cloning. Tahap ini dilakukan penerapan metode Jaccard. Analisis dilakukan menggunakan aplikasi MOBILEdit Forensics Express dan export kedalam laporan dengan format xls. Percakapan yang telah didapat dari proses export dapat dilihat pada Tabel 2.

Tabel 2. Percakapan WAG

\begin{tabular}{ll}
\hline Nama & \multicolumn{1}{c}{ Percakapan } \\
\hline Nia & Ndra apa yang kamu lakukan!! \\
Indra & lah..aku salah apa \\
Luqman & $\begin{array}{l}\text { TOLOL otak mu kamu taruh mana, guru sampai } \\
\text { keluar meninggalkan kelas }\end{array}$ \\
Suci & dasar indra gak berpikir dulu kalau ngomong \\
Dimas & iya GOBLOK amat sih lo ndra gak mikir amat \\
& Sekarang kita semua yang rugi gegara satu orang \\
Nia & TOLOL ini
\end{tabular}

\begin{tabular}{|c|c|}
\hline Indra & $\begin{array}{l}\text { Iya maafin aku tadi aku keceplosan ngatain ibu } \\
\text { guru }\end{array}$ \\
\hline Suci & makanya BEGOK jangan dipelihara atuh... \\
\hline Luqman & iya KAMPRET memang kok teman kita satu ini \\
\hline Dimas & $\begin{array}{l}\text { sekarang kita gak mau tau lo harus tanggung jawab } \\
\text { ndra }\end{array}$ \\
\hline Indra & $\begin{array}{l}\text { Iya-iya nanti aku yang nyamperin ibu guru untuk } \\
\text { minta maaf }\end{array}$ \\
\hline Luqman & Dasar BEGOK lo ndra \\
\hline Dimas & Iya BEGOK amat sih lu \\
\hline
\end{tabular}

Hasil percakapan yang telah didapatkan akan dilakukan text mining untuk mempercepat pencarian dan untuk mengefisienkan proses identifikasi cyberbullying. Gambaran pada sistem dapat dilihat pada Gambar 6.

\section{DIGITAL FORENSICS}

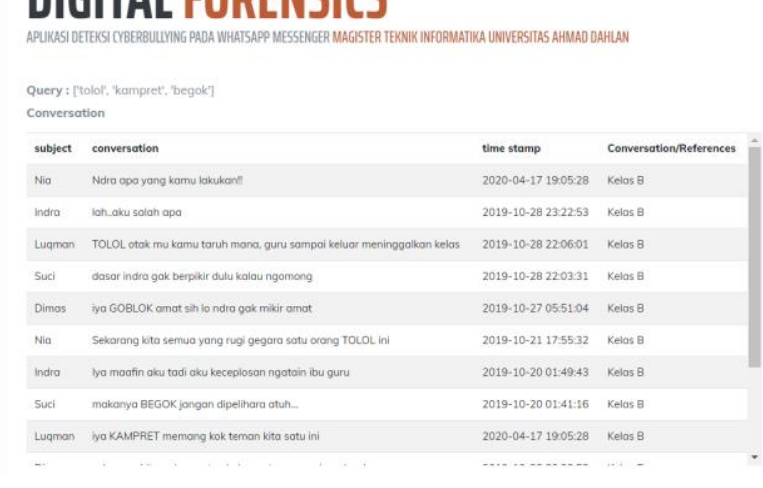

Gambar 6. Hasil upload data percakapan

Proses case folding dan tokenizing dari data sample dapat dilihat pada Tabel 3.

Tabel 3. Proses Case Folding dan Tokenizing

\begin{tabular}{llll}
\hline Nama & Kalimat Asli & Case Folding & Tokenizing \\
\hline \multirow{4}{*}{ Nia } & Ndra apa yang & ndra apa yang & ndra, apa, \\
& kamu & kamu & yang, kamu \\
& lakukan!! & lakukan!! & lakukan \\
Indra & lah..aku salah & lah..aku salah & lah, aku, \\
& apa & apa & salah, apa \\
& TOLOL otak & tolol otak mu & tolol, otak, \\
& mu kamu taruh & mana, guru & mu, kamu \\
& mana, guru & sampai keluar & guru, sampana, \\
& sampai keluar & meninggalkan & keluar, \\
& meninggalkan & kelas & meninggalkan, \\
& kelas & & kelas \\
Luqman & & dasar indra & dasar, indra, \\
& & gak berpikir & gak, berpikir, \\
& dasar indra gak & dulu kalau & dulu, kalua, \\
& berpikir dulu & ngomong \\
\hline \multirow{2}{*}{ Suci } & kalau ngomong & ngomong &
\end{tabular}

Tahap yang dilanjutkan setelah tahap tokenizing adalah tahap stopword removal dan tahap stemming dari data sample dapat dilihat pada Tabel 4.

Tabel 4. Stopword Removal dan Stemming 


\begin{tabular}{|c|c|c|c|}
\hline Nama & Tokenizing & $\begin{array}{l}\text { Stopword } \\
\text { Removal }\end{array}$ & Stemming \\
\hline & $\begin{array}{l}\text { ndra, apa, } \\
\text { yang, kamu }\end{array}$ & ndra, lakukan & ndra, laku \\
\hline $\mathrm{Nia}$ & lakukan & & \\
\hline Indra & $\begin{array}{l}\text { lah, aku, salah, } \\
\text { apa }\end{array}$ & salah & salah \\
\hline Luqman & $\begin{array}{l}\text { tolol, otak, mu, } \\
\text { kamu taruh, } \\
\text { mana, guru, } \\
\text { sampai, keluar, } \\
\text { meninggalkan, } \\
\text { kelas }\end{array}$ & $\begin{array}{l}\text { tolol, otak, mu, } \\
\text { taruh, guru, } \\
\text { meninggalkan, } \\
\text { kelas }\end{array}$ & $\begin{array}{l}\text { tolol, otak, } \\
\text { mu, taruh, } \\
\text { guru, } \\
\text { tinggal, } \\
\text { kelas }\end{array}$ \\
\hline Suci & $\begin{array}{l}\text { dasar, indra, } \\
\text { gak, berpikir, } \\
\text { dulu, kalua, } \\
\text { ngomong }\end{array}$ & $\begin{array}{l}\text { dasar, indra, } \\
\text { gak, berpikir, } \\
\text { ngomong }\end{array}$ & $\begin{array}{l}\text { dasar, } \\
\text { indra, gak, } \\
\text { pikir, } \\
\text { omong }\end{array}$ \\
\hline
\end{tabular}

Gambaran pada sistem jika kata sudah melalui tahap prepocessing dapat dilihat pada Gambar 7.

\section{DIGITAL FORENSICS}

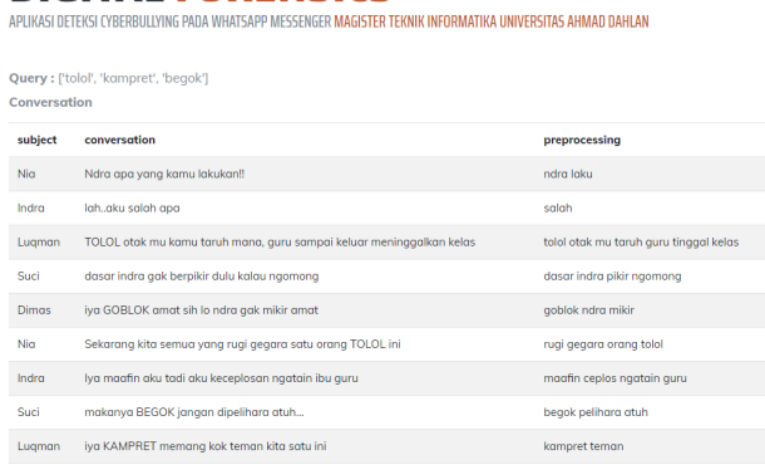

Gambar 7. Hasil prepocessing pada sistem

Hasil sample stemming akan dimasukkan didalam Tabel 5 untuk melakukan pembobotan kata setiap kata yang telah didapatkan.

Tabel 5 Frekuensi Term

\begin{tabular}{|c|c|c|c|c|c|}
\hline Term & Nia & Indra & Luqman & Suci & Dimas \\
\hline ndra & 1 & & 1 & & 1 \\
\hline laku & 1 & & & & \\
\hline rugi & 1 & & & & \\
\hline gara & 1 & & & & \\
\hline orang & 1 & & & & \\
\hline tolol & 1 & & 1 & & \\
\hline salah & & 1 & & & \\
\hline maaf & & 2 & & & \\
\hline ceplos & & 1 & & & \\
\hline kata & & 1 & & & \\
\hline iya & & 1 & 1 & & 1 \\
\hline sampai & & 1 & & & \\
\hline
\end{tabular}

\begin{tabular}{lll} 
guru & 1 & 1 \\
otak & 1 \\
mu & 1 \\
taruh & 1 \\
tinggal & 1 \\
kelas & 1 \\
kampret & 1 \\
\hline
\end{tabular}

Sampel pembobotan kata pada sistem dapat dilihat pada Gambar 8.

\section{DIGITAL FORENSIC \\ APLIKASI DETEKSI CYBERBULLYING PADA WHATSAPP MESSENGER MAGIST}

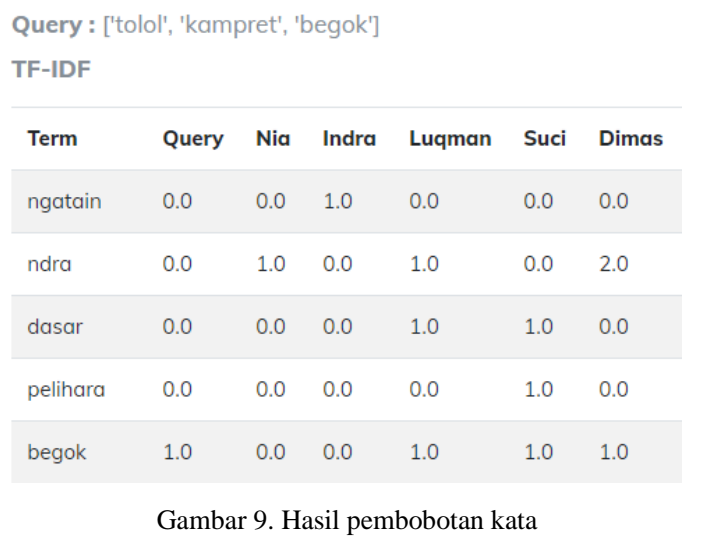

Dari sample frekuensi yang didapat maka dilakukan perhitungan metode Jaccard menggunakan Persamaan (1)

$\operatorname{Jaccard}\left(\right.$ Nia, Query) $=\frac{|3|}{|5|}=0,17 \times 100 \%=17 \%$

Jaccard (Indra, Query) $=\frac{|0|}{|7|}=0 \times 100 \%=0 \%$

Jaccard (Luqman, Query) $=\frac{|3|}{|14|}=0,21 \times 100 \%=21 \%$

Jaccard (Suci, Query) $=\frac{|1|}{|8|}=0,13 \times 100 \%=13 \%$

Jaccard (Dimas, Query) $=\frac{|2|}{|11|}=0,18 \times 100 \%=18 \%$

Dari perhitungan Jaccard diperoleh tingkat cyberbullying oleh Nia, Indra, Luqman, Suci, dan Dimas secara berturut-turut sebesar $17 \%, 0 \%, 21 \%, 13 \%$, dan 18\%. Data dalam sistem dapat dilihat pada Gambar 10.
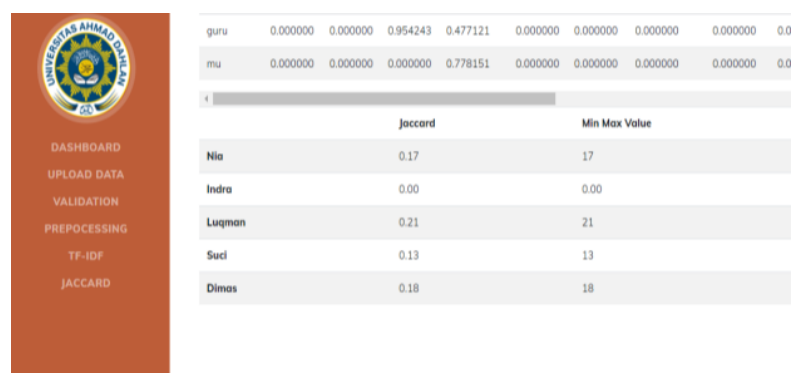


\section{Gambar 10. Hasil Jaccard}

Hasil perhitungan sistem pada Gambar 10 dan perhitungan menggunaan persamaan Jaccard secara perhitungan manual memiliki $100 \%$ kesamaan.

\subsection{Reporting}

Hasil analisis yang telah dilakukan didapatkan data dari proses akuisisi menggunakan aplikasi MOBILEdit Forensics Express. Data yang berhasil didapatkan adalah percakapan dalam WAG untuk mengidentifikasi cyberbullying. Format yang didapatkan untuk dianalisis adalah format xls dan dapat melakukan identifikasi cyberbullying dengan tingkat bullying yang berbedabeda. Hasil pada sistem yang telah dibuat juga memiliki akurasi yang baik karena hasil perhitungan manual dengan hasil perhitungan didalam sistem sesuai.

\section{Kesimpulan}

Berdasarkan hasil analisis dan percobaan pada penelitian yang telah dilakukan membuktikan bahwa metode NIST dapat mempermudah proses investigasi mulai dari pengangkatan barang bukti sampai dengan tahap pelaporan barang bukti. Metode Jaccard mampu mengidentifikasi bullying dengan tingkat yang berbeda, nilai presentasi pelaku tertinggi yang didapat yaitu $21 \%$ kata teridentifikasi $79 \%$ lainnya kata tidak teridentifikasi, dan pelaku dengan nilai terendah yang didapat $13 \%$ kata teridentifikasi $87 \%$ lainnya kata tidak teridentifikasi. Perhitungan menggunakan aplikasi dan perhitungan secara manual didapatkan kesamaan $100 \%$.

\section{Ucapan Terimakasih}

Penelitian ini didukung oleh Direktorat Riset dan Pengabdian Masyarakat, Direktorat Jenderal Penguatan Riset dan Pengembangan Kementerian Riset, Teknologi, dan Pendidikan Tinggi Republik Indonesia dengan Surat Kontrak Tahun Anggaran 2020 Nomor: PTM-035/SKPP.TT/LPPM UAD/VI/2020

\section{Daftar Rujukan}

[1] D. Apriliani, "Pengaruh media sosial facebook terhadap perilaku cyberbullying pada smk patriot 1 bekasi," vol. 7, no. 1, pp. 23-32, 2018.

[2] S. O'Dea, "Number of smartphone users worldwide from 2016 to 2021,” Statista Research Department, 2020. https://www.statista.com/statistics/330695/number-ofsmartphone-users-worldwide/.

[3] C. P. Barlett, D. A. Gentile, G. Chng, D. Li, and K. Chamberlin, "Social Media Use and Cyberbullying Perpetration: A Longitudinal Analysis," Violence Gend., vol. 5, no. 3, pp. 191197, 2018, doi: 10.1089/vio.2017.0047.

[4] J. Clement, "Number of monthly active WhatsApp users worldwide from April 2013 to March 2020," Statista Research Department, https://www.statista.com/statistics/260819/number-ofmonthly-active-whatsapp-users/.

[5] M. P. Darimis, "Cyberbullying Pada Media Sosial : Menyoroti Perilaku Cyberbullying Menurut Perspektif Model Konseling Realitas," Psikologis, 2020, doi https://doi.org/10.31219/osf.io/2arwb.
[6] P. Widiandana, I. Riadi, and Sunardi, "Analisis investigasi forensik cyberbullying pada Whatsapp Messenger menggunakan metode NIST," Semin. Nas. Teknol. Fak. Tekinik Univ. Krisnadwipayana, pp. 488-493, 2019, [Online]. Available:

https://jurnal.teknikunkris.ac.id/index.php/semnastek2019/arti cle/view/308.

[7] I. Riadi and P. Widiandana, "Mobile Forensics for Cyberbullying Detection using Term Frequency - Inverse Document Frequency ( TF-IDF )," vol. 5, no. 2, pp. 68-76, 2020, doi: 10.26555/jiteki.v5i2.14510.

[8] I. Riadi, A. Yudhana, M. Caesar, and F. Putra, "Akuisisi Bukti Digital Pada Instagram Messenger Berbasis Android Menggunakan Metode National Institute Of Justice ( NIJ ), $" J$. Tek. Inform. dan Sist. Inf. Vol. 4 Nomor 2 Agustus 2018, vol. 4 , pp. 219-227, 2018, [Online]. Available: https://www.researchgate.net/profile/Imam_Riadi/publication/ 327779438_Akuisisi_Bukti_Digital_Pada_Instagram_Messen ger_Berbasis_Android_Menggunakan_Metode_National_Insti tute_Of_Justice_Institute_Of_Justice_Institute_of_Justice_NIJ /links/5ba3e1bf92851ca9ed1.

[9] A. Yudhana, I. Riadi, and I. Anshori, "Analisis Bukti Digital Facebook Messenger Menggunakan Metode Nist," It J. Res. Dev., vol. 3, no. 1, p. 13, 2018, doi: 10.25299/itjrd.2018.vol3(1).1658.

[10] M. Besta et al., "Communication-Efficient Jaccard similarity for High-Performance Distributed Genome Comparisons," Proc. - 2020 IEEE 34th Int. Parallel Distrib. Process. Symp. IPDPS 2020, pp. 1122-1132, 2020, doi: 10.1109/IPDPS47924.2020.00118.

[11] S. Bag, S. K. Kumar, and M. K. Tiwari, "An efficient recommendation generation using relevant Jaccard similarity," Inf. Sci. (Ny)., vol. 483, pp. 53-64, 2019, doi: 10.1016/j.ins.2019.01.023.

[12] D. Van Bruwaene, Q. Huang, and D. Inkpen, "A multi-platform dataset for detecting cyberbullying in social media," Lang. Resour. Eval., 2020, doi: 10.1007/s10579-020-09488-3.

[13] I. Riadi, R. Umar, and A. Firdonsyah, "Forensic tools performance analysis on android-based blackberry messenger using NIST measurements," Int. J. Electr. Comput. Eng., vol. 8, no. 5, pp. 3991-4003, 2018, doi: 10.11591/ijece.v8i5.pp3991-4003.

[14] R. Ayatulloh, K. Noor, R. Umar, and A. Yudhana, "Analisis Media Sosial Facebook Lite dengan tools Forensik menggunakan Metode NIST," vol. 21, no. 2, pp. 125-131, 2020 .

[15] N. Nasirudin, S. Sunardi, and I. Riadi, "Analisis Forensik Smartphone Android Menggunakan Metode NIST dan Tool MOBILedit Forensic Express," J. Inform. Univ. Pamulang, vol. 5, no. 1, p. 89, 2020, doi: 10.32493/informatika.v5i1.4578.

[16] K. Khairunnisak, H. Ashari, and A. P. Kuncoro, "Analisis Forensik Untuk Mendeteksi Keaslian Citra Digital Menggunakan Metode Nist," J. Resist. (Rekayasa Sist. Komputer), vol. 3, no. 2, pp. 72-81, 2020, doi: 10.31598/jurnalresistor.v3i2.634.

[17] R. Sistem et al., "Analisis Recovery Bukti Digital Skype berbasis Smartphone Android Menggunakan Framework NIST," vol. 1, no. 10, pp. 682-690, 2021.

[18] S. K. Saad, R. Umar, and A. Fadlil, "Analisis Forensik Aplikasi Dropbox Pada Android Menggunakan Metode NIST," Semin. Nas. Din. Inform., pp. 119-123, 2020.

[19] S. Vijayarani, M. J. Ilamathi, M. Nithya, A. Professor, and M. P. Research Scholar, "Preprocessing Techniques for Text Mining -An Overview," vol. 5, no. 1, pp. 7-16.

[20] P. W. Imam Riadi, Sunardi, "Investigasi Cyberbullying pada WhatsApp Menggunakan Digital Forensics," vol. 1, no. 10, pp. 730-735, 2021.

[21] O. Nurdiana, J. Jumadi, and D. Nursantika, "Perbandingan Metode Cosine Similarity Dengan Metode Jaccard Similarity Pada Aplikasi Pencarian Terjemah Al-Qur'an Dalam Bahasa Indonesia," J. Online Inform., vol. 1, no. 1, p. 59, 2016, doi: 10.15575/join.v1i1.12.

[22] K. R, "Simple Query Suggestion untuk Pencarian Artikel 
menggunakan Jaccard Similarity," J. Ilm. Rekayasa dan Manaj. Sist. Inf., vol. 3, pp. 30-34, 2017.

[23] D. K. Muhammad F, Imam M.I.S, "Sistem Rekomendasi Hasil Pencarian Artikel menggunakan Metode Jaccard's Coefficient," J. Transistor Elektro dan Inform. (TRANSSISTOR EI), vol. 2, no. 1-14, 2017.

[24] A. S. Sugiyamto, Bayu S, “Analisa Performa Metode Cosine dan Jaccard pada Pengujian Kesamaan Dokumen,” J. Masy. Inform., vol. 5, pp. 1-8, 2017.

[25] S. Sunardi, A. Yudhana, and I. A. Mukaromah, "Implementasi Deteksi Plagiarisme Menggunakan Metode N-Gram Dan Jaccard Similarity Terhadap Algoritma Winnowing," Transmisi, vol. 20, no. 3, p. 105, 2018, doi: 10.14710/transmisi.20.3.105-110. 